\title{
A Tripartite Game-Theory-Based Cooperation Mechanism for the Electronic Warehouse Receipt Pledge Financing Mode
}

\author{
Junwei Jia $\mathbb{D}^{D}$, Haoyue Zhang $\mathbb{D}$, and Qi Wang $(\mathbb{D}$ \\ School of Management, Beijing Union University, Beijing 100101, China \\ Correspondence should be addressed to Qi Wang; gltwangqi@buu.edu.cn
}

Received 16 November 2021; Accepted 9 December 2021; Published 21 December 2021

Academic Editor: Daqing Gong

Copyright (c) 2021 Junwei Jia et al. This is an open access article distributed under the Creative Commons Attribution License, which permits unrestricted use, distribution, and reproduction in any medium, provided the original work is properly cited.

\begin{abstract}
To explore the electronic warehouse receipt pledge financing cooperation mechanism in the alliance formed between loan enterprises, commercial banks, e-commerce platforms, and logistics enterprises, by constructing a tripartite evolutionary game model, the game equilibrium strategy is then obtained, and the influencing factors of the cooperation mechanism are further simulated. It was found that in this tripartite evolutionary game, the stable strategy combination occurs when the loan enterprise chooses to repay on time, the platform alliance chooses to provide services, and the commercial bank chooses to continue to cooperate. However, heterogeneity exists in the influencing factors for the three-party selection strategy in the game, which is manifested in the fact that the higher the realization rate of the pledge, the more evolution is required in the selection strategy for loan enterprises to continue cooperating. The higher the information service fee, the higher the enthusiasm of the platform alliance in choosing to provide services. Credit levels, loan interest rates, and pledge realization rates are all important factors that affect the choice strategy of commercial banks.
\end{abstract}

\section{Introduction}

The mode for e-commerce supply chain financing is formed by the e-commerce platform as the information center in the supply chain, combined with commercial banks with a large amount of funds, and the logistics enterprise service platform, which alleviates the problem of loan difficulties for small- and medium-sized enterprises. However, the mode for e-commerce supply chain financing is not as mature as that for traditional supply chain financing, and to a certain extent, the theoretical research is lagging behind practical operations. In recent years, the financing model for the e-commerce supply chain has become increasingly mature. Presently, much research has been conducted on the financing mode for online platform supply chains. However, due to a lack of unity in the classification standards, the classification results are inconsistent, and no consistent definition exists in academic circles. It is generally recognized that the financing modes for online platform supply chains can be divided into the electronic order financing mode and the electronic warehouse receipt financing mode.
Therefore, the cooperation mechanism and income distribution among the financing entities of the e-commerce supply chain have become urgent problems to be solved. By constructing a tripartite evolutionary game model, this paper studied the electronic warehouse receipt pledge financing cooperation mechanism, which is of great significance for exploring the financing model of SMEs and alleviating the financing difficulties of them.

\section{Literature Review}

Many scholars have begun to study the related theories for e-commerce supply chain financing, and the recent related research mainly focuses on the financing model for e-commerce supply chains $[1,2]$, credit guarantee and evaluation issues $[3,4]$, risk management and control issues [5-7], behavioral decision-making issues [8], and cooperation mechanisms $[9,10]$. In the research on cooperation mechanisms, scholars at home and abroad have studied the cooperation mechanism for financing e-commerce supply chains with different subjects and methodologies, including 
the interaction between subjects $[11,12]$, income distribution mechanism [13-15], information sharing mechanism $[16,17]$, and the analysis of the influencing factors on decision-making [18]. Some scholars took e-commerce companies and logistics companies as the main game agent. Their research found that a fair and reasonable benefit distribution mechanism and cooperation trust mechanism can promote the stability of cooperation between the two parties [19]. Liu used evolutionary game theory to construct an evolutionary game model of cooperation between financing companies and e-commerce companies under the characteristics of bounded rationality and analyzed the evolution process, stabilization strategies, and influencing factors of the two parties' cooperation strategies [20]. In addition, some scholars took electronic warehouse receipt financing as an example. Based on the perspective of bank risk aversion, they studied the issue of incentive strategies of banks for third-party platforms when third-party platforms have hidden moral hazards under joint credit and entrusted credit. By studying the feasibility and complexity of warehouse receipt pledge financing [21], Jairath proposed the warehouse receipt pledge financing model and risk prevention strategies of financial institutions and financing companies in the warehouse receipt pledge financing method [22]. From the existing research, game theory has been increasingly utilized in the research on supply chain financing, and different financing modes for supply chains and different participants in supply chain financing have been studied. In this research, the most commonly used game theory research methods are the Stackelberg game method [23], cooperative game method [24], and evolutionary game method [25].

Currently, the research on cooperation in supply chain financing at home and abroad has developed to some extent, but there are still research gaps. First, most scholars have primarily studied the cooperation mechanism for e-commerce supply chain financing in pairs and have seldom studied the game between the three parties in e-commerce supply chain financing. Second, most scholars have paid more attention to the electronic order financing mode and have seldom studied the electronic warehouse receipt pledge financing mode. What needs to be pointed out is that the electronic warehouse receipt pledge financing mode involves more cooperation among the various subjects compared with the electronic order financing mode, because it involves the intervention of logistics enterprises. While scholars have mainly studied the electronic warehouse receipt financing mode [26-28], there has been little research on its cooperation mechanism, and thus, it is of great practical significance to study the relevant cooperation mechanism of the electronic warehouse receipt financing mode. This paper analyzes the multiparty cooperation strategy of the electronic warehouse receipt financing model, then uses evolutionary game theory to study the tripartite evolutionary game stability strategy between the participants in this model, identifies the key influencing factors of the cooperation relationship among the participants, and evaluates the impact of the influencing factors on the cooperation mechanism.

\section{Research Model}

The participants in supply chain financing for platformbased e-commerce generally include commercial bank B, loan enterprise $E$, e-commerce platform $\mathrm{P}$, and logistics enterprise L. All the participants are interrelated and restrict each other. Through cooperation, the Internet and cloud computing are used to share resources and information to achieve a win-win situation, and thus, they play an important role in e-commerce supply chain financing. This paper assumes that in the process for electronic warehouse receipt pledge financing, the supervision warehouse is provided by the logistics enterprises under the e-commerce platform $\mathrm{P}$, and it completes the storage and supervision of the pledge. Therefore, the main body of the tripartite game studied in this paper is the platform alliance $U$ (the alliance formed by the e-commerce platform and the logistics enterprises), the commercial bank $\mathrm{B}$, and the loan enterprise $E$.

\subsection{Analysis of the Cooperation Strategies of the Parties.} Based on the electronic warehouse receipt financing mode and the relationship among the participants, this paper constructs the cooperation mechanism under this financing mode. If the member of SMEs on the platform alliance $U$ wants to obtain loans from the commercial bank $\mathrm{B}$, the inventory of the enterprise needs to be transported to the logistics enterprise in the platform alliance $U$, and the logistics enterprise will then generate the bill of goods of the warehouse voucher online. Loan enterprise $E$ then submits the application materials and electronic warehouse receipts to commercial bank $\mathrm{B}$, which decides whether to lend the enterprise according to the capital flow, information flow, logistics, and electronic warehouse receipts of the small- and medium-sized enterprises provided by the platform alliance $\mathrm{U}$. This paper studies the follow-up game of the three parties to engage in to avoid risks, make the cooperation sustainable, and achieve a win-win situation after the loan enterprise $E$ has obtained the loan from the commercial bank B.

The main function of platform alliance $U$ in the electronic warehouse receipt pledge financing business is to provide information services for commercial bank B. The main information provided includes the relevant information on electronic credit evaluation and follow-up information. In addition, when the loan firm $E$ defaults, platform alliance $U$ spreads its default information through the network. If platform alliance $U$ wants to increase punishment for defaulting enterprises, it may decide whether to provide follow-up information for commercial bank B according to factors including the difficulty of data acquisition of loan enterprise $E$ and the cost of information services. Therefore, platform alliance U's strategic choices in this game include both service provision and denial of service. After the loan enterprise $E$ obtains the loan from the commercial bank B through the platform alliance $U$, it may not be able to repay the loan on time due to changes in the project yield. Therefore, the loan enterprise $E$ has two strategies in the game: timely repayment and overdue default. For commercial bank B, the follow-up behavior of loan 
enterprise $E$ will directly affect commercial bank B's future credit evaluation, and they will carry out credit rating for the enterprise through the financial credit of the loan enterprise $E$ and the follow-up information provided by the platform alliance $U$. Once the credit rating has been lowered into an unacceptable range for commercial bank $B$, they will suspend their cooperation with the loan enterprise E. If the future credit level of loan enterprise $E$ remains within the acceptable range for commercial bank $\mathrm{B}$, they will not change their original strategy and will choose to continue with the cooperation strategy. Therefore, the strategies of commercial bank B in this game include continuing cooperation and suspending cooperation.

To sum up, the strategies of loan enterprise $E$ are timely repayment and overdue default, while platform alliance $U$ can provide services or deny services, and commercial bank $\mathrm{B}$ can continue or suspend cooperation.

3.2. Premises of the Evolutionary Game Model. It is assumed that the game subjects in the model are commercial bank B, platform alliance $U$, and loan enterprise $E$. The model also assumes the following premises:

Premise 1: due to the limitation of objective conditions such as information asymmetry, limited knowledge, and cognitive level of the decision-makers, the decision-making behavior of the three parties in the game does not completely follow the hypothesis of a rational economic man that is a bounded rationality and random game.

Premise 2: if the loan enterprise $E$ defaults after the deadline, the platform alliance $U$ will advertise its dishonest behavior across the network to punish it, and the commercial bank B will punish loan enterprise $E$ by charging it a fine.

Premise 3: there are many factors that affect the pledge rate. For the convenience of this study, this paper assumes that the pledge rate is only affected by the credit level of enterprises.

Premise 4: in the situation where commercial bank B suspends cooperation, lending enterprise $E$ can obtain loans from other financial institutions, and the loan interest rate will be fixed and higher than that of commercial bank B.

Premise 5: this model conducts research on commercial banks, platform alliances, loan enterprises, and other financial institutions only and is not affected by other institutions.

3.3. Parameter Setting. In this financing model, the amount of financing that commercial bank B lends to lending enterprise $E$ is $\lambda_{i} \alpha M$, with the credit level of lending enterprise $E$ being $\lambda_{i}$, expressed as an indicator that measures the default risk of small- and medium-sized enterprises that need financing $\left(0<\lambda_{i}<1\right)$. The higher the credit level of smalland medium-sized enterprises, the higher the pledge rate promised by commercial bank $\mathrm{B}$.

The probability of loan enterprise $E$ repaying on time is expressed as $x$, and the probability of overdue default is $1-x$. The probability of platform alliance $U$ adopting the strategy of providing services is expressed as $y$, and the probability of adopting the strategy of negative cooperation is $1-y$. The probability of commercial bank B adopting the strategy of continuing cooperation is expressed as $z$, and the probability of adopting the strategy of suspending cooperation is $1-z$.

In order to facilitate the analysis of problems, the parameter settings for the evolutionary game model are shown in Table 1.

3.4. Establishment of the Income Matrix. According to the model's assumptions and table of parameter settings, the income matrix for the three subjects is determined, and it is shown in Table 2.

According to the game income matrix of each subject in Table 2, the expected income and average income of loan enterprise $E$, platform alliance $U$, and commercial bank B can be calculated respectively, as shown in Table 3.

3.5. Equilibrium Analysis. Considering the relationship between loan enterprise $E$, platform alliance $U$, and commercial bank B in the dynamic game process, and factoring in the constraints, the equilibrium stability point is judged, as shown in Table 4.

Among the eight equilibrium points obtained, the equilibrium point satisfying Pareto optimality is that in the process of this tripartite evolutionary game, the strategy combination that causes the system to reach the final stable state occurs when the loan enterprise $E$ chooses to repay on time, the platform alliance $U$ chooses to provide services, and the commercial bank B chooses to continue to cooperate. $E_{8}(1,1,1)$.

\section{Results and Discussions}

To answer the question of how to stimulate the cooperation enthusiasm of loan enterprise $E$, platform alliance $\mathrm{U}$, and commercial bank $\mathrm{B}$ and thus achieve a win-win situation among the three parties, it is necessary to analyze the influencing factors on the selection strategy of the three parties. The analysis of evolutionary stability strategy is based on certain constraints, such as $\lambda_{1}>\lambda_{2}>\lambda_{3}>\lambda_{4}, \quad r_{1}<r<r_{2}<\beta, \quad K>C$ and $\varepsilon>\lambda_{i} \alpha+r+r_{1}$. Changing the constraints may have an impact on the evolution of the system. Therefore, MATLAB R2018 B numerical simulation was used to analyze the impact of credit level $\left(\lambda_{i}\right)$, loan interest rate $(r)$, information service fee $(K)$, and pledge realization rate $(\varepsilon)$ on the evolutionary stability of the system.

4.1. The Influence of Credit Level on System Evolution. The credit level $\left(\lambda_{1}\right)$ values are $0,0.5$, and 0.9 , respectively. As can be seen from Figure 1, at that time, $\lambda_{1}=0$, that is, the credit level was not within the lowest acceptable range of commercial bank B, and commercial bank B chooses 
TABLE 1: Game model parameter settings.

\begin{tabular}{|c|c|c|}
\hline Parameters & Variable & Variable description \\
\hline$\alpha$ & Pledge rate & Pledge rate before credit evaluation \\
\hline$\lambda_{i}$ & Credit level & $\begin{array}{l}\text { Measure the credit level of the loan enterprise. The value range is } 0-1, i=1,2,3,4 \text {. Among } \\
\text { them, } \lambda_{1}>\lambda_{2}>\lambda_{3}>\lambda_{4}\end{array}$ \\
\hline$\lambda_{i} \alpha$ & Adjusted pledge rate & The higher the credit level, the greater the pledge rate \\
\hline$\beta$ & Project return rate & The income of loan enterprise $E$ after obtaining the loan \\
\hline$r$ & Loan interest rate & Lending interest rate of commercial bank B \\
\hline$r_{1}$ & $\begin{array}{c}\text { Interest rate of absorption and } \\
\text { storage }\end{array}$ & Cost born by commercial bank B \\
\hline$r_{2}$ & Loan interest rate $\mathrm{B}$ & $\begin{array}{l}\text { After the commercial bank B suspends their cooperation, the loan enterprise } E \text { obtains the } \\
\text { loan interest rate from other financial institutions, in which } r_{2}>r\end{array}$ \\
\hline$\varepsilon$ & $\begin{array}{l}\text { Rate of appreciation/ } \\
\text { depreciation }\end{array}$ & $\begin{array}{c}\text { At the end of the loan period, the pledge of the loan enterprise } E \text { has depreciated or } \\
\text { appreciated }\end{array}$ \\
\hline$M$ & Value of pledge & This parameter is related to the ler \\
\hline Q & Amount of financing & The amount of financing obtained by loan enterprise $E$ from other financial ins \\
\hline$K$ & Information service fee & $\begin{array}{l}\text { The information service fee paid by the commercial bank B to obtain the information service } \\
\text { of the platform alliance } U\end{array}$ \\
\hline C & Information service cost & Cost of providing information services born by platform alliance $U$ \\
\hline$f$ & Membershi & Membership fee paid by loan enterprise $E$ to platform alliance $U$ \\
\hline$h$ & Logistics storage fee & $\begin{array}{c}\text { Logistics storage expenses paid by loan enterprise } E \text { to logistics companies in platform } \\
\text { alliance } U\end{array}$ \\
\hline$P$ & $\begin{array}{l}\text { Alliance penalty for breach of } \\
\text { contract }\end{array}$ & $\begin{array}{c}\text { Penalty paid to commercial bank B when platform alliance U refuses to provide information } \\
\text { services }\end{array}$ \\
\hline$D$ & $\begin{array}{l}\text { Enterprise penalty for breach } \\
\text { of contract }\end{array}$ & $\begin{array}{c}\text { When enterprise } E \text { defaults within the time limit, platform alliance } U \text { will impose a credit } \\
\text { punishment on it }\end{array}$ \\
\hline$L$ & $\begin{array}{l}\text { Penalty for overdue breach of } \\
\text { contract }\end{array}$ & The fine demanded by commercial bank B when enterprise $E$ defaults within the time limit \\
\hline
\end{tabular}

TABLE 2: Game benefit matrix table.

\begin{tabular}{|c|c|c|c|c|c|}
\hline \multirow{2}{*}{\multicolumn{2}{|c|}{ Game player }} & \multicolumn{4}{|c|}{ Loan enterprise } \\
\hline & & \multicolumn{2}{|c|}{ Repayment on time } & \multicolumn{2}{|l|}{ Overdue default } \\
\hline & & \multicolumn{4}{|c|}{ Commercial bank } \\
\hline $\begin{array}{l}\text { Platform } \\
\text { alliance }\end{array}$ & $\begin{array}{l}\text { Provision of } \\
\text { services }\end{array}$ & $\begin{array}{l}\text { Continue to } \\
\text { cooperate } \\
(\beta-r) \lambda_{1} \alpha M-f-h \\
f+h+K-C \\
\left(r-r_{1}\right) \lambda_{1} \alpha M-K \\
(\beta-r) \lambda_{2} \alpha M-h \\
h-P \\
\left(r-r_{1}\right) \lambda_{2} \alpha M+P\end{array}$ & $\begin{array}{l}\text { Suspension of } \\
\text { cooperation } \\
\begin{array}{c}\left(\beta-r_{2}\right) Q-f-h \\
f+h+K-C \\
-K \\
\left(\beta-r_{2}\right) Q-h \\
h-P \\
P\end{array}\end{array}$ & $\begin{array}{c}\text { Continue to cooperate } \\
\begin{array}{c}(1+r+\beta) \lambda_{3} \alpha M-M-f-h-D-L \\
f+h+K-C \\
\varepsilon M-\left(1+r+r_{1}\right) \lambda_{3} \alpha M+L-K \\
(1+r+\beta) \lambda_{4} \alpha M-M-h-D-L \\
h-P \\
\varepsilon M-\left(1+r+r_{1}\right) \lambda_{4} \alpha M+L+P\end{array}\end{array}$ & $\begin{array}{l}\text { Suspension of } \\
\text { cooperation } \\
\begin{array}{c}\left(\beta-r_{2}\right) Q-f-h \\
f+h+\delta-C_{1} \\
-K \\
\left(\beta-r_{2}\right) Q-h \\
h-P \\
P\end{array}\end{array}$ \\
\hline
\end{tabular}

the strategy of suspending cooperation. When the credit level of loan enterprise $E$ is 0.5 and 0.9 ; that is, with the increasing credit level of loan enterprise $E$, commercial bank $\mathrm{B}$ chooses the strategy of continuing cooperation. For loan enterprise $E$, the level of credit has little influence on which strategy it chooses. As can be seen in the figure, the loan enterprise $E$ chooses the strategy of repayment on time under different credit levels, because the original intention of the loan enterprise $E$ is to expand reproduction through financing, increase the scale of the enterprise, and attempt to earn additional income. However, once it defaults, the loan enterprise $E$ will face punishment and the pledge cannot be recovered, resulting in huge losses. For platform alliance $U$, the credit level of loan enterprise $E$ does not affect its information service for commercial banks. Therefore, the credit level has no effect on the strategy choice of platform alliance $U$.
4.2. The Influence of Loan Interest Rate on System Evolution. The loan interest rates $(r)$ are $2.5 \%, 4 \%$, and $6 \%$, respectively. As can be seen from Figure 2, when the loan interest rate is $2.5 \%$, that is, when the loan interest rate is low, commercial bank $B$ chooses the strategy of suspending cooperation. When the loan interest rate is $4 \%$ and $6 \%$, that is, with increasing loan interest rates, commercial bank B chooses the strategy of continuing cooperation. For loan enterprise $E$, when the loan interest rate is within a reasonable range, the loan interest rate does not affect which strategy it chooses, but it will affect its evolution rate to this strategy. For platform alliance $U$, the level of the loan interest rate will not affect its interests in providing information services for commercial banks. Therefore, the level of the loan interest rate has no effect on platform alliance U's strategy choice. 
TABLE 3: Income statement of different strategies of stakeholders.

\begin{tabular}{lr}
\hline Strategy & Expected return and average expected return \\
\hline Loan enterprise $E$ repays the loan on time & $\begin{array}{l}E_{E_{1}}=z \alpha M(\beta-r)\left[y \lambda_{1}+(1-y) \lambda_{2}\right] \\
+(1-z)\left(\beta-r_{2}\right) Q-y f-h\end{array}$ \\
Lending enterprise $E$ overdue default & $E_{E_{2}}=z \alpha M(\beta+1+r)\left[y \lambda_{3}+(1-y) \lambda_{4}\right]$ \\
& $+(1-z)\left(\beta-r_{2}\right) Q-y f-h-z(M+D+L)$ \\
Loan enterprise $E$ average income & $\overline{E_{E}}=x E_{E_{1}}+(1-x) E_{E_{2}}$ \\
Platform alliance U provides services & $E_{U_{1}}=f+h+K-C$ \\
Platform alliance U denies service & $E_{U_{2}}=h-P$ \\
Platform alliance U averages revenue & $\overline{E_{U}}=y E_{U_{1}}+(1-y) E_{U_{2}}$ \\
& \\
Commercial bank B continues to cooperate & $E_{B_{1}}=x \lambda_{2} \alpha M\left(r-r_{1}\right)+x y \alpha M\left(r-r_{1}\right)\left(\lambda_{1}-\lambda_{2}\right)$ \\
Commercial bank B discontinues cooperation & $+(1-x) \varepsilon M-(1-x) \alpha M\left(1+r+r_{1}\right)\left[y \lambda_{3}+(1-y) \lambda_{4}\right]$ \\
Average return of commercial bank B & $-y K+(1-y) P+(1-x) L$ \\
& $E_{B_{2}}=(1-y) P-y K$ \\
& $E_{B}=z E_{B_{1}}+(1-z) E_{B_{2}}$
\end{tabular}

TABLE 4: Stability analysis of equalization points.

\begin{tabular}{|c|c|c|c|}
\hline Equilibrium point & Eigenvalue & Eigenvalue \pm & Stability \\
\hline$E_{1}(0,0,0)$ & $\begin{array}{c}Q_{1}=0 \\
Q_{2}=K+f+P-C \\
Q_{3}=\varepsilon M-\lambda_{4} \alpha M\left(1+r+r_{1}\right)+L \\
Q_{1}=\lambda_{2} \alpha M(\beta-r)-\lambda_{1} \alpha M(\beta+1+r)+M+D+L\end{array}$ & $\begin{array}{l}Q_{1}=0 \\
Q_{2}>0 \\
Q_{3}>0 \\
Q_{1}>0\end{array}$ & Instability point \\
\hline$E_{2}(0,0,1)$ & $\begin{array}{c}Q_{1}=\lambda_{2} \alpha M(\beta-r)-\lambda_{4} \alpha M(\beta+1+r)+M+D+L \\
Q_{2}=K+f+P-C \\
Q_{3}=-\left(\varepsilon M-\lambda_{4} \alpha M\left(1+r+r_{1}\right)+L\right) \\
Q_{1}=0\end{array}$ & $\begin{array}{l}Q_{1}>0 \\
Q_{2}>0 \\
Q_{3} \prec 0 \\
Q_{1}=0\end{array}$ & Saddle point \\
\hline$E_{3}(0,1,0)$ & $\begin{array}{c}Q_{2}=-(K+f+P-C) \\
Q_{3}=\varepsilon M-\lambda_{3} \alpha M\left(1+r+r_{1}\right)+L \\
Q_{1}=\lambda_{1} \alpha M(\beta-r)-\lambda_{3} \alpha M(\beta+1+r)+M+D+L\end{array}$ & $\begin{array}{l}Q_{2} \prec 0 \\
Q_{3}>0 \\
Q_{1}>0\end{array}$ & Saddle point \\
\hline$E_{4}(0,1,1)$ & $\begin{array}{c}Q_{2}=-(K+f+P-C) \\
Q_{3}=-\left[\varepsilon M-\lambda_{3} \alpha M\left(1+r+r_{1}\right)+L\right] \\
Q_{1}=0\end{array}$ & $\begin{array}{l}Q_{2} \prec 0 \\
Q_{3} \prec 0 \\
Q_{1}=0\end{array}$ & Saddle point \\
\hline$E_{5}(1,0,0)$ & $\begin{array}{c}Q_{2}=K+f+P-C \\
Q_{3}=\lambda_{2} \alpha M\left(r-r_{1}\right) \\
Q_{1}=-\left[\lambda_{2} \alpha M(\beta-r)-\lambda_{4} \alpha M(\beta+1+r)+M+D+L\right]\end{array}$ & $\begin{array}{l}Q_{1}=0 \\
Q_{2}>0 \\
Q_{3}>0 \\
Q_{1}<0\end{array}$ & Instability point \\
\hline$E_{6}(1,0,1)$ & $\begin{array}{c}Q_{2}=K+f+P-C \\
Q_{3}=\alpha_{2} M\left(r_{2}-\lambda_{2} r\right) \\
O_{1}=0\end{array}$ & $Q_{2}>0$ & Saddle point \\
\hline$E_{7}(1,1,0)$ & $\begin{array}{c}Q_{1}=0 \\
Q_{2}=-(K+f+P-C) \\
Q_{3}=\lambda_{1} \alpha M\left(r-r_{1}\right) \\
Q_{1}=-\left[\lambda_{1} \alpha M(\beta-r)-\lambda_{2} \alpha M(\beta+1+r)+M+D+L\right]\end{array}$ & $\begin{array}{l}Q_{1}=0 \\
Q_{2} \prec 0 \\
Q_{3} \succ 0\end{array}$ & Saddle point \\
\hline$E_{8}(1,1,1)$ & $\begin{array}{c}\left.\lambda_{1} \alpha M(\beta-r)-\lambda_{3} \alpha M(\beta+1+r)+M+D+L\right] \\
Q_{2}=-(K+f+P-C) \\
Q_{3}=-\lambda_{1} \alpha M\left(r-r_{1}\right)\end{array}$ & $\begin{array}{l}Q_{2} \prec 0 \\
Q_{3} \prec 0\end{array}$ & Stable point \\
\hline
\end{tabular}

4.3. Impact of the Information Service Fee on System Evolution. The values of the information service fee $(K)$ are 50, 70, and 90, respectively. As can be seen in Figure 3, when the information service fee is 50 , that is, when the information service fee is low, the platform alliance $U$ chooses the denial of service strategy. Hence, when the cost of information services is low, platform alliance $U$ cannot obtain additional income from this financing business, and it will therefore choose the strategy of refusing to provide services. When the information service fee is 70 or 90 , that is, with the increase of the information service fee, platform alliance $U$ chooses the strategy of providing services. For loan enterprise $E$, the level of the information service fee will not affect their strategic choice. For commercial bank B, the main factor affecting the strategy choice is the subsequent credit level change of loan enterprise E. The level of the information service fee will not directly affect the final decision of commercial bank $\mathrm{B}$, and thus, the level of the information service fee will not affect the strategy choice of commercial bank B.

4.4. Influence of the Liquidation Rate of the Pledge on System Evolution. The realization rates of the pledge $(\varepsilon)$ are $0.5,1$, and 2 , respectively. As can be seen in Figure 4, when the realization rate of the pledge is 0.5 , that is, when the final value of the pledge decreases, commercial bank $\mathrm{B}$ chooses the strategy of suspending cooperation. When the loan enterprise $E$ defaults, commercial bank B has the right to dispose its pledge and make up for the loss of time. Once the 


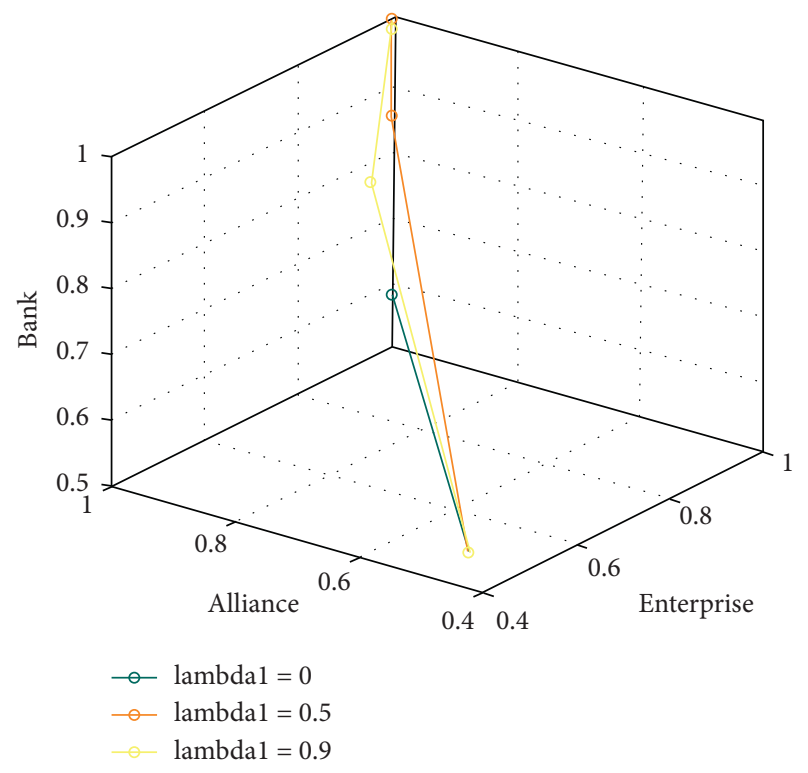

FIGURE 1: Three-party evolutionary game trajectory under different credit levels.

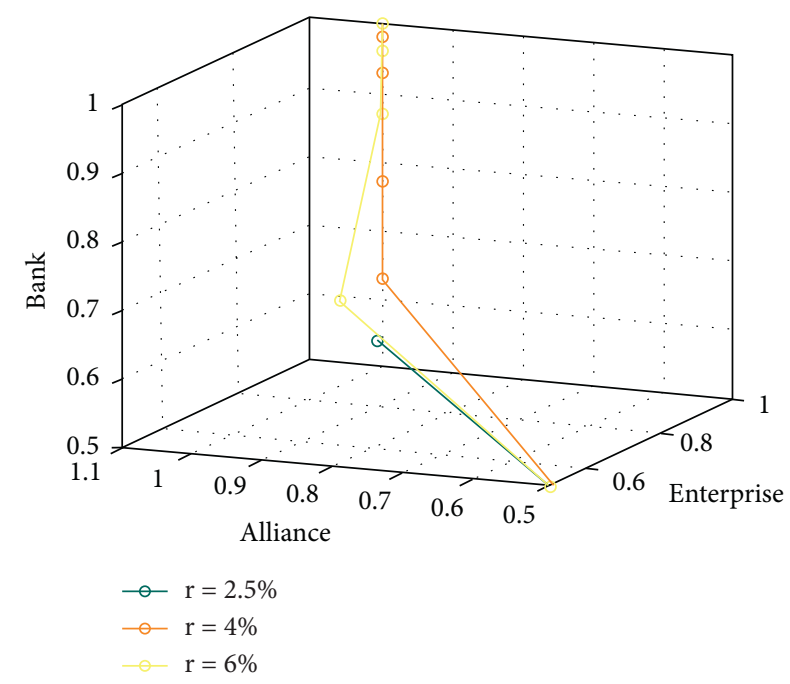

FIGURE 2: Three-party evolutionary game trajectory under different loan interest rates.

pledge depreciates seriously, commercial bank B will incur huge losses when the loan enterprise $E$ defaults. Therefore, in order to avoid such risks, when the realization rate of the pledge is small, the commercial bank B chooses to suspend the cooperation strategy. When $\varepsilon=1, \varepsilon=2$, that is, the pledge does not depreciate, commercial bank B chooses the strategy of continuing cooperation. For the loan enterprise $E$, when $\varepsilon=0.5$, the probability of the loan enterprise $E$ choosing to repay on time and defaulting on time is similar, because when the pledge has been seriously devalued, the overall loss of the loan enterprise $E$ when defaulting on time might be small. When $\varepsilon=1, \varepsilon=2$, that is, when the pledge does not depreciate or even appreciate, the loan enterprise chooses the repayment strategy on time, because at this time, if the loan enterprise $E$ defaults from overdue payment, it

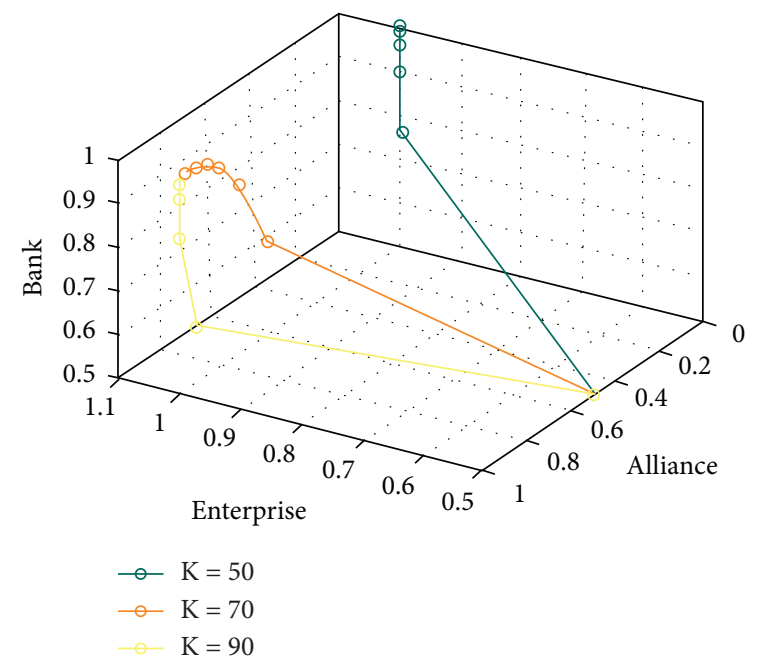

FIGURE 3: Three-party evolutionary game trajectory under different information service fees.

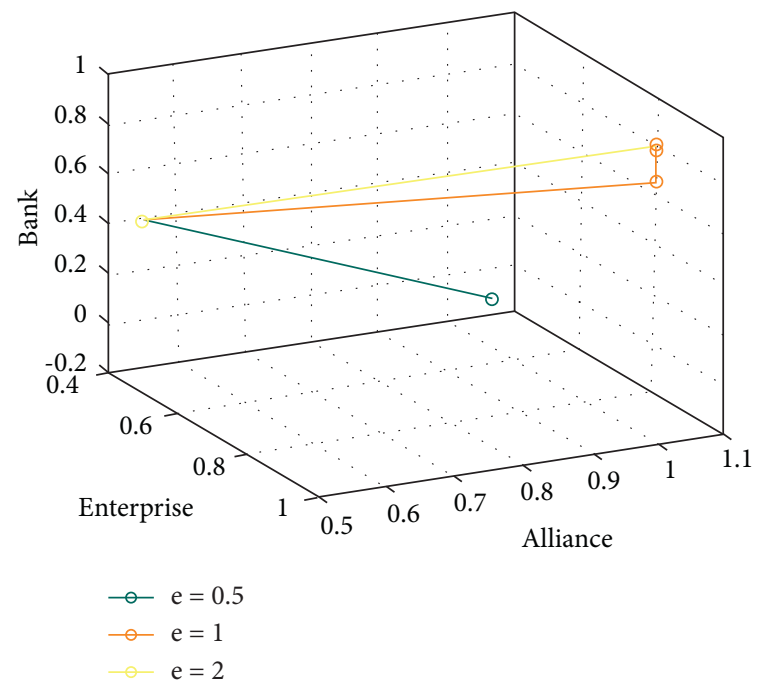

FIGURE 4: The trajectory of the three-party evolutionary game under different realization rates of pledges.

will face greater losses. For platform alliance $U$, the realization rate of the pledge will not affect its interests in providing information services for commercial banks. Therefore, the realization rate of the pledge has no effect on platform alliance U's strategy choice.

\section{Conclusions and Recommendations}

\subsection{Research Conclusion}

(1) In the process of the tripartite evolutionary game, the strategy combination that makes the system reach the final stable state is that loan enterprise $E$ chooses to repay on time, platform alliance $U$ chooses to provide services, and commercial bank B chooses to continue cooperation.

(2) The size of the pledge realization rate is an important factor affecting the loan enterprise E's strategy 
choice. When the pledge realization rate is small, the loan enterprise $E$ will choose the overdue default strategy, because when the pledge depreciates seriously and the pledge realization rate is lower than the pledge rate, the choice of the overdue default strategy may be more profitable to the loan enterprise when the operation fails. With the gradual increase of the realization rate of the pledge, the greater the loss incurred by the loan enterprise $E$ in choosing the default strategy. Therefore, a higher quality pledge can increase the probability of the loan enterprise $E$ repaying on time.

(3) The level of the information service fee is an important factor affecting the platform alliance U's selection strategy. When the information service fee is high, the platform alliance $U$ chooses the strategy of providing services. According to the revenue matrix of the platform alliance $U$, the main factor affecting its revenue is the information service fee. Therefore, when the information service fee is high, the platform alliance $U$ will have a higher revenue.

(4) For commercial bank B, the credit level, loan interest rate, and pledge realization rate are important factors that affect its strategic choice. With the continuous improvement of the credit level of loan enterprise $E$, that is, when loan enterprise $E$ has improved credit, commercial bank B chooses to continue the cooperation strategy. In a reasonable range, raising the loan interest rate is beneficial for causing commercial bank B to choose the strategy of continuing cooperation. According to the income matrix of commercial bank $\mathrm{B}$, its income mainly comes from the differences in the interest rate. Therefore, the larger the difference in the interest rate, the higher its income, which tends to cause it to choose the strategy of continuing cooperation. When the realization rate of the pledge is small, that is, when the pledge depreciates seriously, commercial bank B will choose the strategy of suspending cooperation, because when the pledge depreciates seriously, the realization rate of the pledge is lower than the pledge rate, and if the lending enterprise $E$ defaults, commercial bank B may incur huge losses. As the realization rate of the pledge gradually increases, the financing risks borne by commercial bank B gradually decrease, and it tends to choose the strategy of continuing cooperation. Therefore, better quality collateral can increase the probability of commercial bank B continuing to cooperate.

5.2. Relevant Recommendations. (1) Increasing the monitoring of the realization price of the pledge: Commercial Bank $\mathrm{B}$ can give some support to the platform alliance $U$ and help them to establish a "digital warehouse" and other facilities and to realize real-time monitoring of the realization value of the pledge of loan enterprise E. Once the pledge depreciates on a large scale, platform alliance $U$ or commercial bank B can take corresponding measures to reduce their financing risks. (2) Improving the accuracy and reliability of the data provided by platform alliance $U$ : the platform alliance $U$ collects the transaction data and other information of all its member enterprises. The e-commerce platform will then use information processing technologies such as "cloud computing" and "big data" to identify the required information from the noisy and massive information pool. In this process, it is very important to accurately select the useful information, and improving information processing technology will be helpful for data cleaning. (3) Reasonable pricing of the information service fees: when pricing information service fees, platform alliance $\mathrm{U}$ needs to consider not only the cost of providing the service but also that the income of commercial bank $\mathrm{B}$ when participating in e-commerce supply chain financing is higher than that of traditional supply chain financing, and thus, improving the probability of cooperation between commercial bank B and platform alliance $U$ can increase the income of platform alliance $U$.

5.3. Limitations and Future Research Directions. The research conclusions of this article are of practical significance for optimizing the financing model of the e-commerce supply chain, especially for the electronic warehouse receipt financing business. However, this article studied the tripartite cooperation strategy of the electronic warehouse receipt financing model under single-period conditions and did not involve the dynamic game of tripartite cooperation under multi-period conditions, which is also the direction of follow-up research. And with the further development of information technology, blockchain technology can be introduced into e-commerce supply chain financing in the future to further consider changes in the cooperation mechanism among participating entities.

\section{Data Availability}

No data were used in this study.

\section{Conflicts of Interest}

The authors declare that they have no conflicts of interest.

\section{Acknowledgments}

This research was supported by the Humanities and Social Science Research Youth Project of the Ministry of Education (20YJC630175).

\section{References}

[1] M. Castillo and A. Dianat, "Truncation strategies in two-sided matching markets: theory and experiment," Games and Economic Behavior, vol. 98, pp. 180-196, 2016.

[2] Z. Chen, J. Chen, Z. Zhang, and X. Zhi, "Does network governance based on banks' e-commerce platform facilitate supply chain financing?" China Agricultural Economic Review, vol. 11, no. 4, pp. 688-703, 2019. 
[3] P. Kouvelis and W. Zhao, "Who should finance the supply chain? Impact of credit ratings on supply chain decisions," Manufacturing \& Service Operations Management, vol. 20, no. 1, pp. 19-35, 2018.

[4] C. Bruckermann, "Network marketing and state legitimacy in China: regulating trust from physical workplaces to virtual spaces," Economic Anthropology, vol. 8, no. 1, pp. 86-101, 2021.

[5] D. J. A. Gonsalvez and R. R. Inman, "Supply chain shared risk self-financing for incremental sales," The Engineering Economist, vol. 61, no. 1, pp. 23-43, 2016.

[6] Y. N. Si, "Research on the balanced relationship between online consumer behavior and E-commerce service quality based on 5G network," Mobile Information Systems, 2021.

[7] R. Silvestro and P. Lustrato, "Integrating financial and physical supply chains: the role of banks in enabling supply chain integration," International Journal of Operations \& Production Management, vol. 34, no. 3, pp. 298-324, 2014.

[8] W. Jin and J. Luo, "Optimal inventory and insurance decisions for a supply chain financing system with downside risk control," Applied Stochastic Models in Business and Industry, vol. 33, no. 1, pp. 63-80, 2017.

[9] M. Protopappa-Sieke and R. W. Seifert, "Benefits of working capital sharing in supply chains," Journal of the Operational Research Society, vol. 68, no. 5, pp. 521-532, 2017.

[10] M. Wandfluh, E. Hofmann, and P. Schoensleben, "Financing buyer-supplier dyads: an empirical analysis on financial collaboration in the supply chain," International Journal of Logistics Research and Applications, vol. 19, no. 3, pp. 200-217, 2016.

[11] H. Song, K. Yu, and Q. Lu, "Financial service providers and banks' role in helping SMEs to access finance," International Journal of Physical Distribution \& Logistics Management, vol. 48, no. 1, pp. 69-92, 2018.

[12] D. A. Wuttke, C. Blome, H. Sebastian Heese, and M. Protopappa-Sieke, "Supply chain finance: optimal introduction and adoption decisions," International Journal of Production Economics, vol. 178, pp. 72-81, 2016.

[13] B. Wang, D.-C. Huang, H.-y. Li, and J.-Y. Ding, "Optimal decisions and financing strategies selection of supply chain with capital constraint," Mathematical Problems in Engineering, vol. 2016, pp. 1-14, 2016.

[14] K. Xu, H. P. Ding, and X. Z. Bao, "Supply chain financing model and income distribution based on the fourth party logistics bilateral platform," Journal of Beijing Jiaotong University, vol. 4, pp. 93-101, 2016.

[15] Y. X. Zeng, P. Yuan, and Y. W. Zhang, "Decision analysis of fresh food E-commerce supply chain with different dominations from the perspective of game theory," Journal of Nanjing Audit University, no. 5, pp. 55-64, 2019.

[16] T. H. Nazifa and K. K. Ramachandran, "Information sharing in supply chain management: a case study between the cooperative partners in manufacturing industry," Journal of System and Management Sciences, vol. 9, no. 1, pp. 19-47, 2019.

[17] M. Kolotylo-Kulkarni, W. Xia, and G. Dhillon, "Information disclosure in e-commerce: a systematic review and agenda for future research," Journal of Business Research, vol. 126, pp. 221-238, 2021.

[18] J. Z. Zhan and R. Lu, "Research on the selection strategy of supply chain financing modes under the restriction of retailers' purchase funds," Journal of Management in Engineering, vol. 30, no. 3, pp. 106-113, 2016.

[19] Y. Zhang, F. Rong, and Z. Wang, "Research on cold chain logistic service pricing-based on tripartite Stackelberg game," Neural Computing \& Applications, vol. 32, no. 1, pp. 213-222, 2020.
[20] X. L. Liu and H. Yang, "A game analysis of the evolution of the cooperation mechanism between farmers and agricultural products E-commerce enterprises based on the perspective of relationship contracts," Operations Research and Management, vol. 30, no. 6, pp. 96-102, 2021.

[21] J. Yu and X. T. Zhuang, "Research on incentive strategies of third-party B2B platforms based on bank downside risk avoidance," Operations Research and Management, vol. 29, no. 9, pp. 96-102, 2021.

[22] M. S. Shalendra, M. S. Jairath, E. Haque, and V. A. Peter, "Issues limiting the progress in negotiable warehouse receipt (NWR) financing in India\$," Agricultural Economics Research Review, vol. 29, no. 1, pp. 53-59, 2016.

[23] A. Babaeinesami, H. Tohidi, and S. M. Seyedaliakbar, "A closed loop Stackelberg game in multi-product supply chain considering information security: a case study," Advances in Production Engineering and Management, vol. 15, no. 2, pp. 223-246, 2020.

[24] T. T. Zhang, L. Wang, and H. Chen, "The game of interests in China's unified carbon market: a perspective of sustainability," Environmental Engineering and Management Journal, vol. 19, no. 9, pp. 1535-1541, 2020.

[25] H. Hu, Q. Wu, S. Han, and Z. Zhang, "Coordination of dualchannel supply chain with perfect product considering sales effort," Advances in Production Engineering \& Management, vol. 15, no. 2, pp. 192-203, 2020.

[26] J. P. Tu and X. Yang, "Research on performance evaluation of supply chain financing model based on e-commerce platform," Management World, vol. 7, pp. 182-183, 2013.

[27] W. J. Li and H. W. Ma, "Research on supply chain financing model based on B2B," Technology Management, vol. 4, pp. 68-72, 2011.

[28] A. Burinskiene, "New challenges for supply chain: electronic invoicing and its use perspective," Journal of Logistics, Informatics and Service Science, vol. 5, no. 1, pp. 31-42, 2018. 